\title{
Evaluation of Logistics 4.0 Potentials Based On Transportation Safety and Security for a Logistics Company \\ Elifcan GÖÇMEN ${ }^{1 *}$
}

\begin{abstract}
Transportation sector faces growing pressure to handle the global trends while meeting the customer demands. Fourth Industrial Revolution (Industry 4.0) is one of these challenges and gained attraction by the researchers and practitioners of all sectors in recent years and expected to continue its challenging effect in the next decades. This revolution is named as Logistics 4.0 in the context of Industry 4.0 implications in logistics. This era prompts the logistics companies to transit to smarter facilities. In this paper, the problem is denoted as selection of the optimum logistics service provider (LSP) for a logistics firm regarding transportation safety, security, quality and cost criteria based on fourth industrial revolution. The LSP selection problem is to choose the appropriate LSP to meet the increasing demands and provide the good or service in the logistics chain. Analytic Hierarchy Process (AHP), which is one of the most widely used multi-criteria decision making methods (MCDM) is proposed to identify and rank the LSPs, and Fuzzy approach is also developed to obtain most important criteria and best LSPs. Safety and security criteria is obtained as two important criteria in the fuzzy approach with the percentage for selection of best LSP is \% 83.7 while security is the most important criteria in the AHP with 0,568 score. Computational results are promising for the decision makers in terms of both solution simplicity and usefulness for logistics sector.
\end{abstract}

Keywords: Transportation safety and security, logistics 4.0, Ahp, fuzzy approach

\section{Bir Lojistik Şirketi İçin Taşımacılık Emniyeti ve Güvenliği Kapsamında Lojistik 4.0 Potansiyellerinin Değerlendirilmesi}

ÖZET: Ulaştırma sektörü, müşteri taleplerini karşılarken küresel eğilimleri ele almak konusunda artan bir baskı ile karşı karşıyadır. Dördüncü Sanayi Devrimi (Endüstri 4.0) bu zorluklardan biridir ve son yıllarda tüm sektörlerin araştırmacıları ve uygulayıcıları tarafından ilgi kazanmıştır ve önümüzdeki yıllarda da etkisini sürdürmesi beklenmektedir. Bu devrim, lojistikte Endüstri 4.0 sonuçları bağlamında Lojistik 4.0 olarak adlandırılmaktadır. Bu dönem lojistik şirketlerini daha akıllı tesislere geçmeye teşvik etmektedir. Bu makalede problem, bir lojistik firması için dördüncü sanayi devrimine dayanan nakliye emniyeti, güvenlik, kalite ve maliyet kriterleri ile ilgili optimum lojistik hizmet sağlayıcısının (LHS) seçimi olarak belirtilmiştir. LHS seçim problemi, lojistik zincirinde hizmet veya ürün sağlamak ve artan talepleri karşılamak için en uygun LHS'yi seçmektir. En yaygın kullanılan çok kriterli karar verme yöntemlerinden (ÇKKV) biri olan Analitik Hiyerarşi Süreci (AHP), LHS' leri tanımlamak ve sıralamak için önerilmiştir ve en önemli kriterleri ve en iyi LHS'leri elde etmek için Bulanık yaklaşım da geliştirilmiştir. Emniyet, AHP'de 0,568 değerle en önemli kriter olurken güvenlik ve emniyet kriteri, bulanık yaklaşımda en iyi LHS seçmek için \% 83.7 ile en önemli iki kriter olmaktadır. Hesaplama sonuçları, karar vericiler açısından lojistik sektörü için çözüm basitliği ve kullanışlılığg açısından umut vericidir.

Anahtar Kelimeler: Taşıma emniyeti ve güvenliği, lojistik 4.0, Ahp, bulanık yaklaşım

Elifcan GÖÇMEN (Orcid ID: 0000-0002-0316-281X), Munzur Üniversitesi, Mühendislik Fakültesi, Endüstri Mühendisliği Bölümü, Tunceli

Corresponding author: Elifcan GÖÇMEN, elifcangocmen@munzur.edu.tr

Geliş tarihi / Received: 05-03-2020

Kabul tarihi / Accepted: 14-07-2020 


\section{INTRODUCTION}

Logistics companies have been searching new ways to deliver fast, cost efficiently. In addition to these requirements, global world prompts the firms to evaluate other parameters in this sector. Besides to classical attributes of transportation such as cost, time, etc., safety, security and quality requirements are regarded nowadays. Logistics 4.0 tools can be considered as a promising alternative for a safer and more quality transportation. Logistics 4.0 tools are useful to improve of logistics systems (Kauf, 2016).

Nowadays, transportation sector has been forced to adapt to "Industry 4.0" era. Challenges are mainly with vehicle communication, transport operations, and automated warehouses in this system. Smart transportation systems are conducted by Resource Planning, Warehouse Management Systems, Transportation Management Systems, Intelligent Transportation Systems and Information Security applications. A real-time tracking of transports, modern transportation handling system, safety and security processes are the main challenges for this area.

Logistics 4.0 has gained attention by technological transformation, legislation and global competition. Industry 4.0 is defined in the logistics sector as Logistics 4.0. The key words are CyberPhysical Systems (CPS), Internet of Things (IoT), Big Data and Data Mining (DM) and Internet of Services (IoS) for the Logistics 4.0. CPS is used to define the combine the cyber and physical systems. IoT ensures the communication between user and the machines. DM provides the conduct the data due to volume and speed. IoS ensures business model, user and service systems by various providers. To keep up with these challenging issues, novel strategies are needed in all processes of the firms. Identifying and ranking the all strategies requires decision-making methods to evaluate them. Logistics 4.0 provides some solutions such as logistics planning, warehouse operations, intelligent transportation systems, and security flow (Barreto et al., 2017). This study presents a method based on AHP to identify and rank the LSPs to adapt the Industry 4.0. Basic keys of the Industry 4.0 are mainly cloud computing, big data, industrial networking, industrial robotics, three-dimensional prototyping, knowledge-based automation, industrial communication security, virtual reality and artificial intelligence (Simon et al., 2018). Optimum selection is complex since various criteria can conflict each other (Memari et al., 2019). To the best of out knowledge, this study is first to apply Logistics 4.0 sub criteria grouped under the transportation safety and security criteria using both AHP and fuzzy approach to select the best LSPs in the transportation sector. Main contributions are as follows: Developing a decision support system to deal with selection the LSPs for an effective logistics management system. A real world setting is conducted to evaluate the efficiency of the proposed methods. A sensitivity analysis is conducted to validate the proposed approach. Then, logistics 4.0 implications are grouped under four criteria including safety, security, cost and quality in the transportation sector. Third, the problem is solved by both AHP with certain judgments and a fuzzy approach with linguistic variables under uncertain judgments. Thus, comparison of both methods is conducted.

The rest of this paper is as follows. Previous works are proposed in Section 2. Section 3 presents the material and methods. Section 4 addresses the results and findings. Section 5 concludes the study and presents the future works.

\section{PREVIOUS WORKS}

Many researchers study the decision-making problems with various criteria using MCDM methods. Few works have used MCDM methods in the transportation sector based on social, economical and human criteria. The papers and provided methods are addressed in Table 1. Luthra and Mangla (2018) identify challenges for supply chain sustainability based on Industry 4.0 in India. They use AHP to rank them and prioritize them. Results show that highest importance is assigned to technological 
challenges. Gürcan et al. (2016) examines the selection of the logistics service provider for a company. They use AHP to evalute the firms based on compatibility, long term relationship, financial performance, reputation criteria. Prakash and Barua (2015) integrate Fuzzy AHP and TOPSIS to implement strategies for the reverse logistics in electronics industry. Fuzzy AHP is used to obtain weights of the implementation barriers and fuzzy TOPSIS is used to prioritize the method solutions. Hasan et al. (2020) use fuzzy TOPSIS and Multi-Choice Goal Programming (MCGP) model for a supplier selection problem. A goal programming approach is proposed to determine the order allocations. A sensitivity analysis is conducted to assess the changes for the Supplier's Cost versus Resilience Index (SCRI). Erdoğan et al. (2018) use MCDM to implement Industry 4.0 applications. They apply AHP-VIKOR methods to obtain the optimal strategy. Jain et al. (2018) propose a supplier selection problem using AHP and TOPSIS. They weight the criteria by AHP, and rank the suppliers by AHP and TOPSIS. Li et al. (2018) present an approach related with third-party reverse logistics provider selection. They use hybrid MCDM and cumulative prospect theory (CPT). Obtained results present that incorporating psychological issues avoid the risks. Tadić et al. (2014) proposes a hybrid fuzzy MCDM to solve the city logistics concept selection. They develop a combined method including DEMATEL, ANP and VIKOR methods. Stević et al. (2020) proposes a new MCDM model to select sustainable supplier in the healthcare sector. They apply a Measurement of Alternatives and Ranking according to Compromise Solution (MARCOS) method. The solutions indicate that MARCOS has ensured an identical ranking. Pamucar et al. (2019) handle a problem related with 3PL provider's selection. They present an integrated method based on the Best Worst Method (BWM) and Weighted Aggregated Sum Product Assessment (WASPAS) method with Multi-Attributive Border Approximation area Comparison (MABAC).

Table 1. Classification table for the preliminary works

\begin{tabular}{lcc}
\hline Study & Problem Definition & Method \\
\hline Tadić et al. (2014) & City logistics concept selection & DEMATEL, ANP, VIKOR \\
Prakash and Barua (2015) & Implement strategies of reverse logistics & Fuzzy AHP, TOPSIS \\
Gürcan et al. (2016) & Selection of the LSP & AHP \\
Erdoğan et al. (2018) & Industry 4.0 applications & AHP-VIKOR \\
Jain et al. (2018) & Supplier selection problem & AHP-TOPSIS \\
Li et al. (2018) & Reverse logistics provider selection & Hybrid MCM, CPT \\
Luthra and Mangla (2018) & Supply chain sustainability & AHP \\
Pamucar et al. (2019) & 3PL provider's selection & BWM, WASPAS, MABAC \\
Stević et al. (2020) & Selection of sustainable supplier & MARCOS \\
Hasan et al. (2020) & Supplier selection problem & Fuzzy TOPSIS, MCGP \\
\hline
\end{tabular}

To the best of our knowledge, Logistics 4.0 implications haven't been grouped under some criteria in the transportation sector. Four criteria including safety, security, cost and quality are considered in this paper. Few works have dealt with the social, economical and human criteria in the preliminary works mentioned above. The previous works also use various methods to compare the results for the selection of the logistics provider. In this paper, the LSP selection problem is solved by both AHP with certain judgments and a fuzzy approach with linguistic variables under uncertain judgments.

\section{MATERIALS AND METHODS}

\section{Problem Definition}

The LSP selection problem is defined as selection of the optimum logistics service provider (LSP) for a logistics firm regarding transportation safety, security, quality and cost criteria based on fourth industrial revolution in this paper. This problem is focused on to choose the appropriate LSP to meet the increasing demands and provide the good or service in the logistics chain. LSP ensures to manage the 
good flows or service between the supply and demand nodes. Cost-effectiveness and time are important metrics for these management processes. Most previous works consider cost mainly instead of various criteria in practice. We divided these metrics into four groups:

Safety: transportation of containers in a safety manner.

Security: transportation of containers in a security manner.

Quality: main objectives, quality measures, optimum service levels.

Cost: expected cost or loss.

This material and method section will address each criterion and the sub criteria. Thus, selection of LPS based on criteria weighting is conducted. The MCDM problem addresses container distribution by trucks to customer points. The transportation network involves logistics firm, LSP, customers. Each LSP has a firm defined image. This is also depending on the evaluation by the decision makers. AHP and Fuzzy approach are used in the study to evaluate these LSPs.

The decision levels of AHP of the Logistics 4.0 are demonstrated in Table 2.

Table 2. The decision levels of AHP for Logistics 4.0

\begin{tabular}{|c|c|c|c|}
\hline \\
\hline & $\begin{array}{l}\text { LEVEL 1: Decision Problem: Optimum Selection Of Logistic Service Provider Consic } \\
\text { 4.0 And Transportation safety and security } \\
\text { LEVEL 2: Criteria: Safety, Security, Quality, Cost } \\
\text { LEVEL 3: Sub Criteria: }\end{array}$ \\
\hline \multicolumn{4}{|c|}{$\begin{array}{ll}\text { Safety } & \text { Security } \\
\text { POD } & \text { STLS }\end{array}$} \\
\hline \multicolumn{4}{|c|}{ EDI $\quad$ GF } \\
\hline \multirow{2}{*}{\multicolumn{4}{|c|}{$\begin{array}{l}\text { PA } \\
A S G H\end{array}$}} \\
\hline & VLS & MFS & $\mathrm{LC}^{*}$ \\
\hline PLS & ASS & PPV & $\mathrm{UC}^{*}$ \\
\hline
\end{tabular}

LEVEL 4: Decision Alternatives: 21 LSPs

In Table 1, main aim addresses the selection of the best LSPs. Then, the main criteria discussed in this paper are safety, security, quality and cost. Cost criteria includes Transportation cost (TC), Staff cost (SC), Insurance cost (IC), Loading cost (LC), Unpredictable cost (UC)*. Those cost types are important to select a LSP. Sub criteria for the Safety, Security, and Quality are obtained from the work by Göçmen and Erol (2018). Table 3 presents the sub criteria and their definitions evaluated in the study.

Table 3. Sub criteria discussed in the study and their definitions

POD (Proof of Delivery)

The user who receives the delivery sends a signature by PDA. Thus, a safe delivery is conducted.

EDI (Electronic Data Interchange)

Data interchanges by Transportation Management System (TMS) and data transfer by Transportation

Management System (TMS) are provided with EDI. A safe data interchange and transfer is conducted.

IOD (Information of Delivery)

Real-time signals are ensured by navigation devices in the trailers in the loading and unloading processes.

TMS (In Trailer Monitoring System)

Video and photograph records are conducted automatically with some actions is ensured on real time in the vehicle.

STLS (Sensor Trailer Locking System)

Vehicle door is controlled whether it is locked or unlocked and coordinate signals are sent. 
Table 3. Sub criteria discussed in the study and their definitions

GF (Geo-Fencing)

This part controls the routes defined of vehicles. Notifications are given if the vehicle arrivals are not completed.

(WMS) Warehouse Management System

The system ensures to define customer requirements and to form new solution and improvement.

(MFS) Material Flow Control Systems

MFS manages controls and optimizes material flow and information by automated warehouse solution systems.

(PA) Portal Applications

The system ensures a transparent system that both the customers and the staffs obtain the similar information.

(ASRS) Automated Storage and Retrieval Systems

ASRS can stock up loading goods to their locations and unload them from shelves.

(ASGH) Automation Systems for Garments on Hanger

AS ensures that garments on hanger are transported, stored, sorted based on orders and they are carried without human touch.

Vertical Lift Systems (VLS)

VLS deal with trays available in automated lift systems. Picking of goods and distribution of them to the operators are carried out.

Pick to Light Systems (PLS)

The system needs ordering of picks and demonstrates the staff labels and product amounts.

Automated Sorter Systems (ASS)

To sort the products is difficult step. Automated solution methods are important for labour-intensive works.

Product Pick by Voice (PPV)

Obtaining requests and sending feedback are provided by PPV. The system ensures the user to use their hands and eyes freely. Order picking works need these systems.

POD (Proof of Delivery)

\section{Method}

The LSP selection problem is defined in the problem definition section. Data related with the problem is obtained by the logistics firm and used to get final importance weights of the criteria determined using AHP and fuzzy logic. Some papers also conduct decision making problems using Fuzzy logic and AHP to compare both methods and the results are efficient and effective (Abdulhasan et al., 2019). AHP and fuzzy logic are compared to evaluate an index and the results reveal that AHP is better than Fuzzy logic (Kadam et al., 2019). A flowchart of the proposed method is depicted in Figure 1.

Table 4 demonstrates the score assignments developed by Saaty (1980) of LSPs based on the safety parameter. AHP is founded to delimit the problems with some axioms (Saaty, 1980). AHP conducts comparing alternatives by defined criteria based on the decision makers' opinions and ranks the alternatives for a comprehensive decision making process. 21 LSPs are evaluated by the decision makers considering historical data. Safety criteria considered in this weighting includes 5 sub criteria mentioned above. These evaluations are based on the decision maker's judgments which are numerical values based on the historical data of the company and thinking of the three experts (computer engineer, industrial engineer and project leader) of R\&D department while the evaluations are based on linguistic variables in fuzzy approach. Weighting of LSP based on Safety criteria is demonstrated in APPENDIX. 


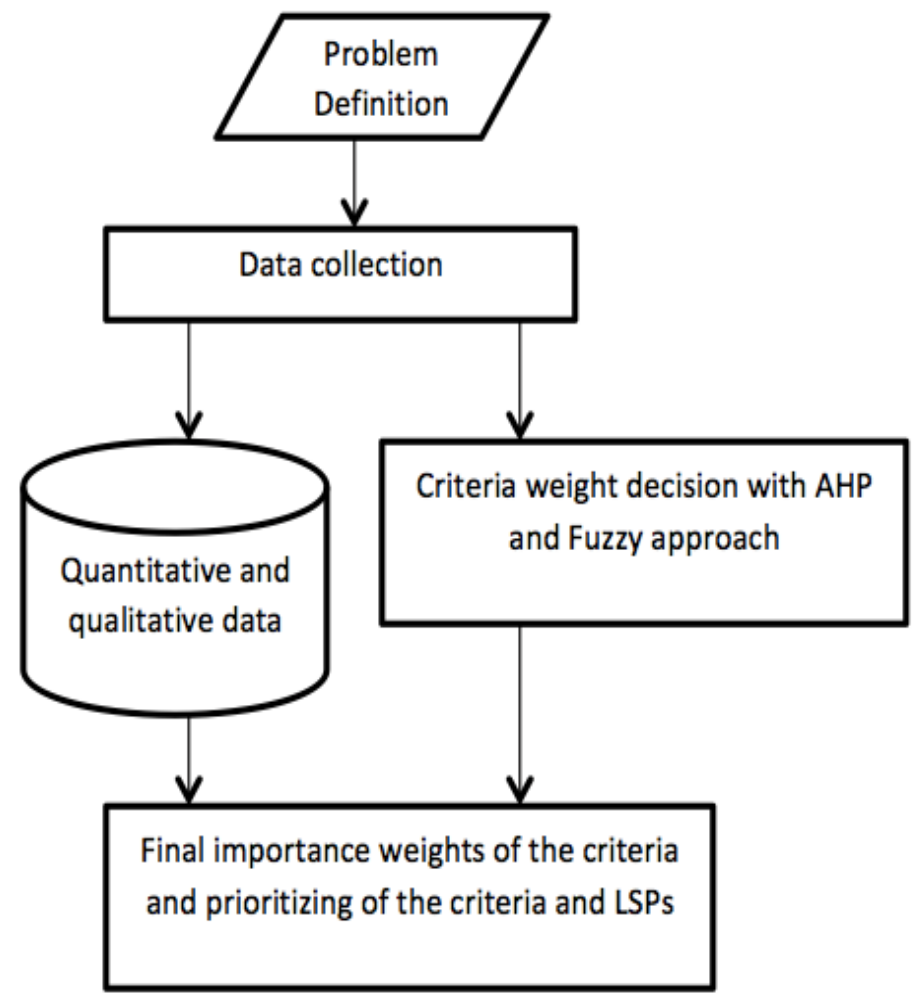

Figure 1. Flowchart of the proposed method

Table 4. Scoring of LSPs based on safety parameter

\begin{tabular}{|c|c|c|c|c|c|c|c|c|c|c|c|c|c|c|c|c|c|c|c|c|c|}
\hline & 1 & 2 & 3 & 4 & 5 & 6 & 7 & 8 & 9 & 10 & 11 & 12 & 13 & 14 & 15 & 16 & 17 & 18 & 19 & 20 & 21 \\
\hline 1 & 1 & 3 & 5 & $1 / 7$ & 9 & $1 / 7$ & $1 / 3$ & 3 & $1 / 5$ & 7 & 3 & $1 / 5$ & 7 & $1 / 3$ & 5 & 5 & 3 & $1 / 7$ & 9 & 5 & $1 / 3$ \\
\hline 2 & $1 / 3$ & 1 & 3 & 5 & 7 & $1 / 5$ & $1 / 7$ & $1 / 5$ & $1 / 9$ & 7 & $1 / 3$ & 5 & 3 & $1 / 5$ & $1 / 5$ & 9 & 7 & $1 / 3$ & 5 & 5 & 7 \\
\hline 3 & $1 / 5$ & $1 / 3$ & 1 & 3 & 9 & $1 / 7$ & $1 / 3$ & 3 & $1 / 5$ & 7 & 3 & $1 / 5$ & 7 & $1 / 3$ & 5 & 5 & 3 & $1 / 7$ & 9 & 5 & $1 / 3$ \\
\hline 4 & 7 & $1 / 5$ & $1 / 3$ & 1 & 5 & $1 / 7$ & 9 & $1 / 7$ & $1 / 3$ & 3 & $1 / 5$ & 7 & 3 & $1 / 5$ & 7 & $1 / 3$ & 5 & 5 & 3 & $1 / 7$ & 9 \\
\hline 5 & $1 / 9$ & $1 / 7$ & $1 / 9$ & $1 / 5$ & 1 & $1 / 7$ & 9 & $1 / 7$ & $1 / 3$ & 3 & $1 / 5$ & 7 & 3 & $1 / 5$ & 7 & $1 / 3$ & 5 & 5 & 3 & $1 / 7$ & 9 \\
\hline 6 & 7 & 5 & 7 & 7 & 7 & 1 & $1 / 3$ & 3 & $1 / 5$ & 7 & 3 & $1 / 5$ & 7 & $1 / 3$ & 5 & 5 & 3 & $1 / 7$ & 9 & 5 & $1 / 3$ \\
\hline 7 & 3 & 7 & 3 & $1 / 9$ & $1 / 9$ & 3 & 1 & 3 & 9 & $1 / 7$ & $1 / 3$ & 3 & $1 / 5$ & 7 & 3 & $1 / 5$ & 7 & $1 / 3$ & 5 & 5 & 3 \\
\hline 8 & $1 / 3$ & 5 & $1 / 3$ & 7 & 7 & $1 / 3$ & $1 / 3$ & 1 & 3 & 5 & 7 & $1 / 5$ & $1 / 7$ & $1 / 5$ & $1 / 9$ & 7 & $1 / 3$ & 5 & 3 & $1 / 5$ & $1 / 5$ \\
\hline 9 & 5 & 9 & 5 & 3 & 3 & 5 & $1 / 9$ & $1 / 3$ & 1 & 9 & $1 / 7$ & $1 / 3$ & 3 & $1 / 5$ & 7 & 3 & $1 / 5$ & 7 & $1 / 3$ & 5 & 5 \\
\hline 10 & $1 / 7$ & $1 / 7$ & $1 / 7$ & $1 / 3$ & $1 / 3$ & $1 / 7$ & 7 & $1 / 5$ & $1 / 9$ & 1 & 3 & 9 & $1 / 7$ & $1 / 3$ & 3 & $1 / 5$ & 7 & 3 & $1 / 5$ & 7 & $1 / 3$ \\
\hline 11 & $1 / 3$ & 3 & $1 / 3$ & 5 & 5 & $1 / 3$ & 3 & $1 / 7$ & 7 & $1 / 3$ & 1 & $1 / 3$ & 3 & $1 / 5$ & 7 & 3 & $1 / 5$ & 7 & $1 / 3$ & 5 & 5 \\
\hline 12 & 5 & $1 / 5$ & 5 & $1 / 7$ & $1 / 7$ & 5 & $1 / 3$ & 5 & 3 & $1 / 9$ & 3 & 1 & 7 & $1 / 5$ & $1 / 7$ & $1 / 5$ & $1 / 9$ & 7 & $1 / 3$ & 5 & 3 \\
\hline 13 & $1 / 7$ & $1 / 3$ & $1 / 7$ & $1 / 3$ & $1 / 3$ & $1 / 7$ & 5 & 7 & $1 / 3$ & 7 & $1 / 3$ & $1 / 7$ & 1 & 3 & 5 & 7 & $1 / 5$ & $1 / 7$ & $1 / 5$ & $1 / 9$ & 7 \\
\hline 14 & 3 & 5 & 3 & 5 & 5 & 3 & $1 / 7$ & 5 & 5 & 3 & 5 & 5 & $1 / 3$ & 1 & 7 & 3 & $1 / 5$ & 7 & $1 / 3$ & 5 & 5 \\
\hline 15 & $1 / 5$ & 5 & $1 / 5$ & $1 / 7$ & $1 / 7$ & $1 / 5$ & $1 / 3$ & 9 & $1 / 7$ & $1 / 3$ & $1 / 7$ & 7 & $1 / 5$ & $1 / 7$ & 1 & 5 & 5 & 3 & $1 / 7$ & 9 & 5 \\
\hline 16 & $1 / 5$ & $1 / 9$ & $1 / 5$ & 3 & 3 & $1 / 5$ & 5 & $1 / 7$ & $1 / 3$ & 5 & $1 / 3$ & 5 & $1 / 7$ & $1 / 3$ & $1 / 5$ & 1 & 3 & $1 / 5$ & 7 & $1 / 3$ & 5 \\
\hline 17 & $1 / 3$ & $1 / 7$ & $1 / 3$ & $1 / 5$ & $1 / 5$ & $1 / 3$ & $1 / 7$ & 3 & 5 & $1 / 7$ & 5 & 9 & 5 & 5 & $1 / 5$ & $1 / 3$ & 1 & 5 & 3 & $1 / 5$ & $1 / 5$ \\
\hline 18 & 7 & 3 & 7 & $1 / 5$ & $1 / 5$ & 7 & 3 & $1 / 5$ & $1 / 7$ & $1 / 3$ & $1 / 7$ & $1 / 7$ & 7 & $1 / 7$ & $1 / 3$ & 5 & $1 / 5$ & 1 & 3 & $1 / 7$ & 9 \\
\hline 19 & $1 / 9$ & $1 / 5$ & $1 / 9$ & $1 / 3$ & $1 / 3$ & $1 / 9$ & $1 / 5$ & $1 / 3$ & 3 & 5 & 3 & 3 & 5 & 3 & 7 & $1 / 7$ & $1 / 3$ & $1 / 3$ & 1 & 5 & $1 / 3$ \\
\hline 20 & $1 / 5$ & $1 / 5$ & $1 / 5$ & 7 & 7 & $1 / 5$ & $1 / 5$ & 5 & $1 / 5$ & $1 / 7$ & $1 / 5$ & $1 / 5$ & 9 & $1 / 5$ & $1 / 9$ & 3 & 5 & 7 & $1 / 5$ & 1 & 9 \\
\hline 21 & 3 & $1 / 7$ & 3 & $1 / 9$ & $1 / 9$ & 3 & $1 / 3$ & 5 & $1 / 5$ & 3 & $1 / 5$ & $1 / 3$ & $1 / 7$ & $1 / 5$ & $1 / 5$ & $1 / 5$ & 5 & $1 / 9$ & 3 & $1 / 9$ & 1 \\
\hline
\end{tabular}

The inputs in the Fuzzy approach include linguistic values and they are fuzzied using triangular membership functions. Fuzzy if-then rules are developed. A fuzzy approach is applied and coded using the Fuzzy Logic Designer Tool in Matlab. Safety, quality, cost, security is inputs, and the selection the best LSP is the output. Developed fuzzy design is depicted in Figure 2. In this design, min- max methods, min implication, max aggregation, centroid defuzzification are used. Ranges are decided as (0-3) for each input variable. 


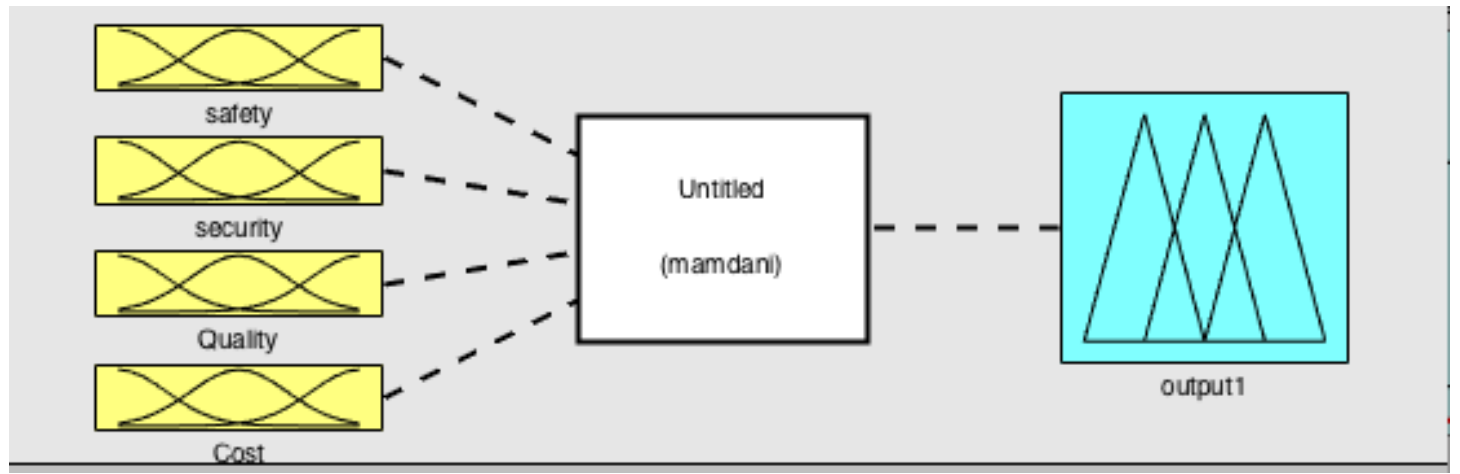

Figure 2. Fuzzy design of the paper

The triangular membership function consisting low, medium, high for inputs is depicted in Figure 3 and. Fuzzy numbers are low $(0,0,1.5)$, Medium $(0,1.5,3)$ High $(1.5,3,3)$. This figure presents the importance levels of inputs evaluated with fuzzy number. The evaluation of safety is low, the input is assigned with numerical value between 0-1.5.

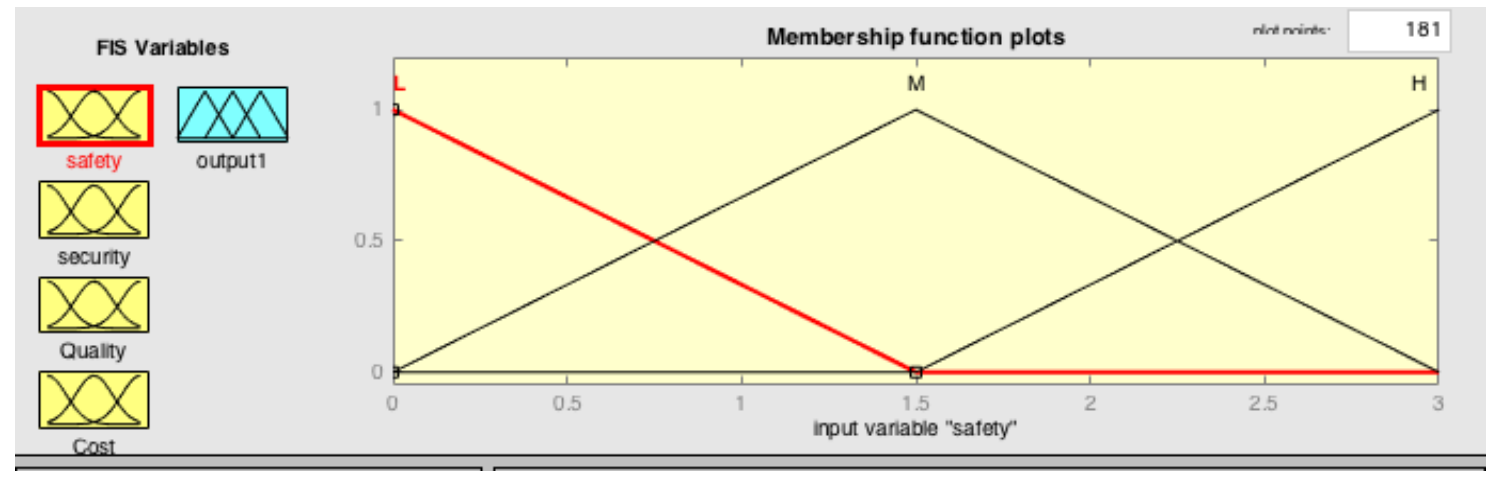

Figure 3. Demonstration of membership function plot for inputs

The triangular membership function is used and includes low, medium, high. Fuzzy numbers are low $(0,0,50)$, Medium $(25,50,75)$ High $(50,100,100)$. This figure defines the output is evaluated with fuzzy numbers.

Decision rule combinations are formed for the discussed problem. The most critical criteria is safety, thus, the rules are developed by high values. Developed rules are as follows:

-If safety is low, security is low, quality is low, cost is low, and then output is low.

-If safety is high, security is high, quality is high, cost is high, and then output is high.

-If safety is low, security is low, quality is medium, cost is medium then output is medium.

-If safety is low, security is low, quality is high, cost is high, and then output is medium.

-If safety is low, security is low, quality is medium, cost is medium, and then output is medium.

-If safety is high, security is high, quality is medium, cost is medium, and then output is high.

\section{RESULTS AND DISCUSSION}

Key terms of Industry 4.0 for logistics sector have been popular in this area. Comprehensive analysis consisting of processes, technology factors is gap in the literature. An approach is required to identify of the process, technical needs including stakeholders for the logistics 4.0 (Barreto et al., 2017). In this section, findings of both methods in which identifying of the processes, technical needs including LSPs is conducted are evaluated. Fuzzy approach is used to decide the most important criteria to select the LSP. Thus, safety and security main criteria are obtained as important parameters. Decision rules are formed by different inputs and success of output are analysed. When safety, security and quality values are increased, best selection of LSP also increases. Some examples are shown in Figure 4-5. 
All inputs are depicted for medium values (1.5) in Figure 4 and the output is 50 percentage successes. Medium judgments for each criterion cannot ensure maximum success. This means that some criteria are more important than the others.

Safety and security values are assigned as 3 number and quality and cost are minimum. The percentage for selection of best LSP is \% 83.7. Figure 5 depicts the importance of these two important criteria.

Figure 6 depicts the importance of the two criteria: Cost and quality. The selection percentage of best LSP is \%16.3. This means that cost and quality criteria are not important as safety and security criteria.

Figure 7 represents the success of the selection of the best LSP in the context of incorporating of safety and security criteria.

Results are obtained by Fuzzy approach and then, comparing the criteria prioritization, AHP is conducted. Each criterion is scored by the decision makers. Then, the weights of each criterion are obtained. Table 5 demonstrates the criteria weights and thus, the most important criteria are security for this transport network. Quality, Safety and Cost are obtained based on their weights, respectively.

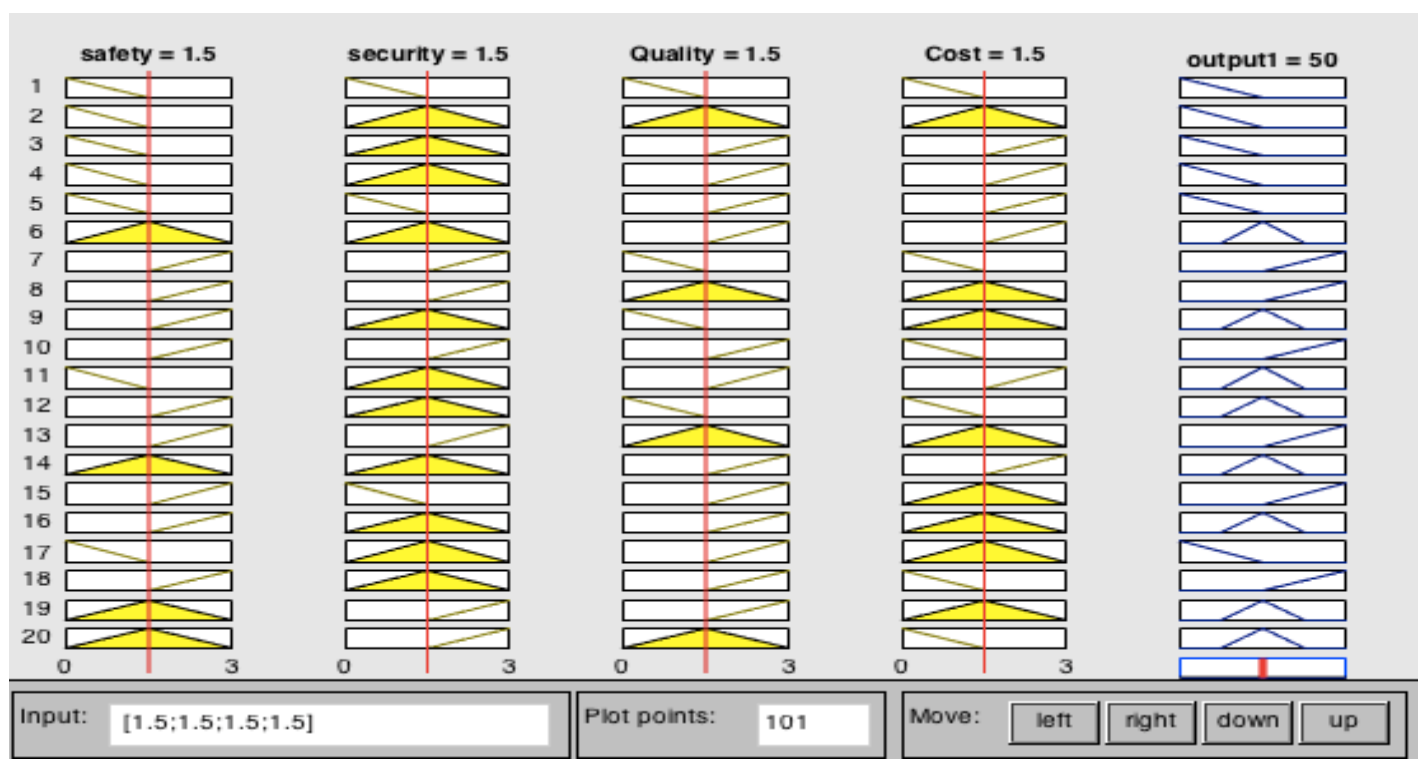

Figure 4. Inputs and outputs based on decision rules

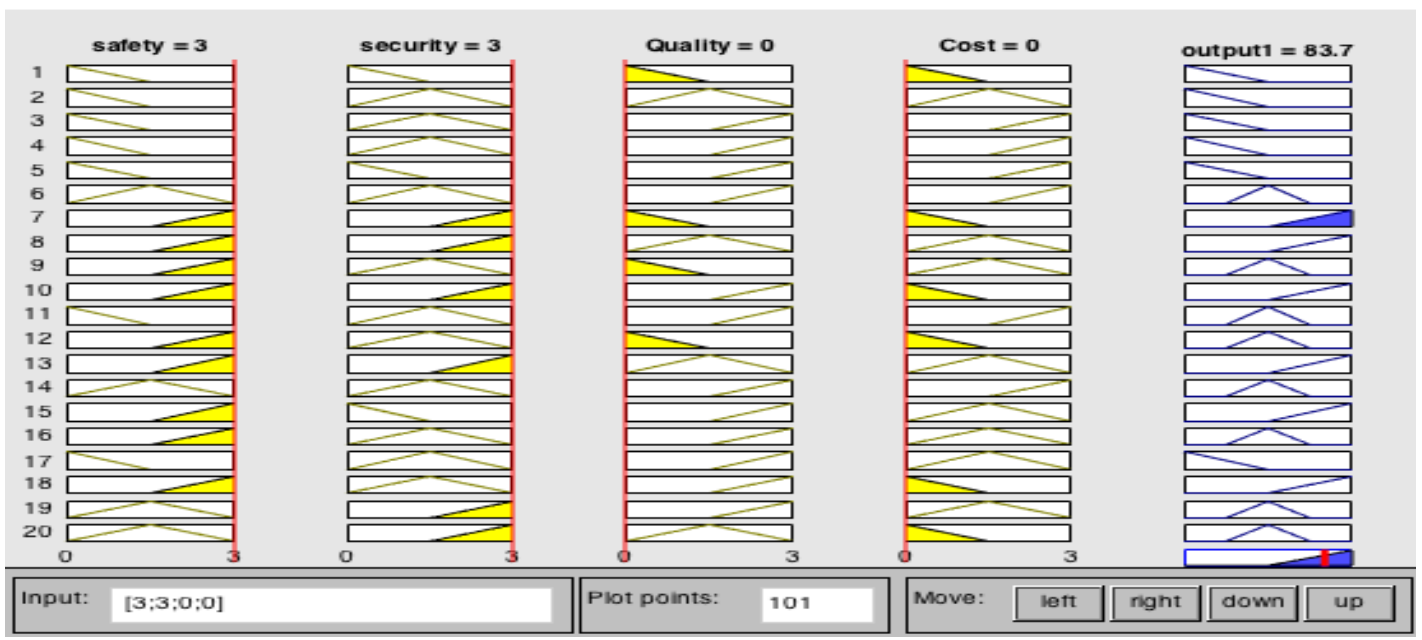

Figure 5. Inputs and outputs based on decision rules (For safety and security) 


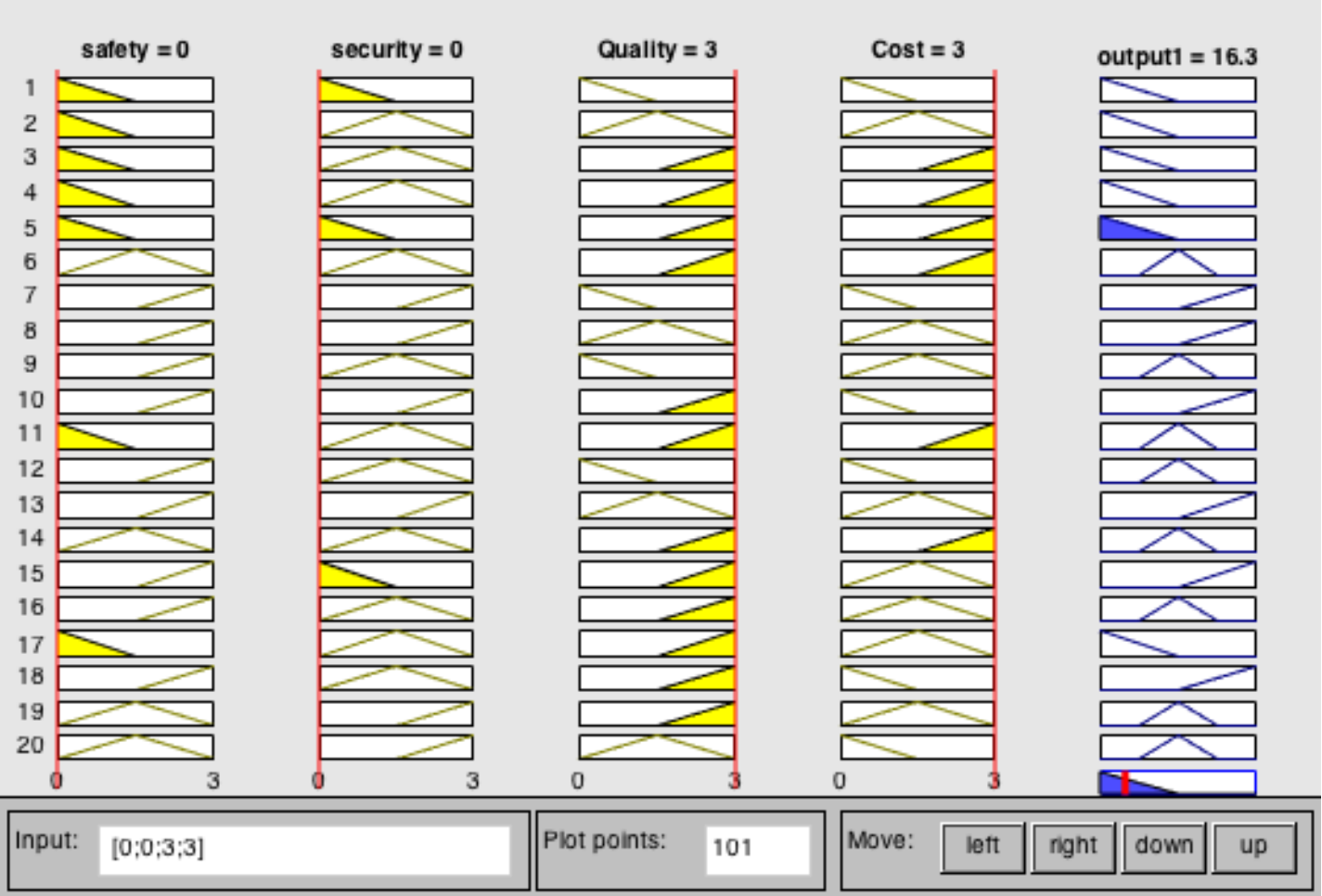

Figure 6. Inputs and outputs based on decision rules (For quality and cost)

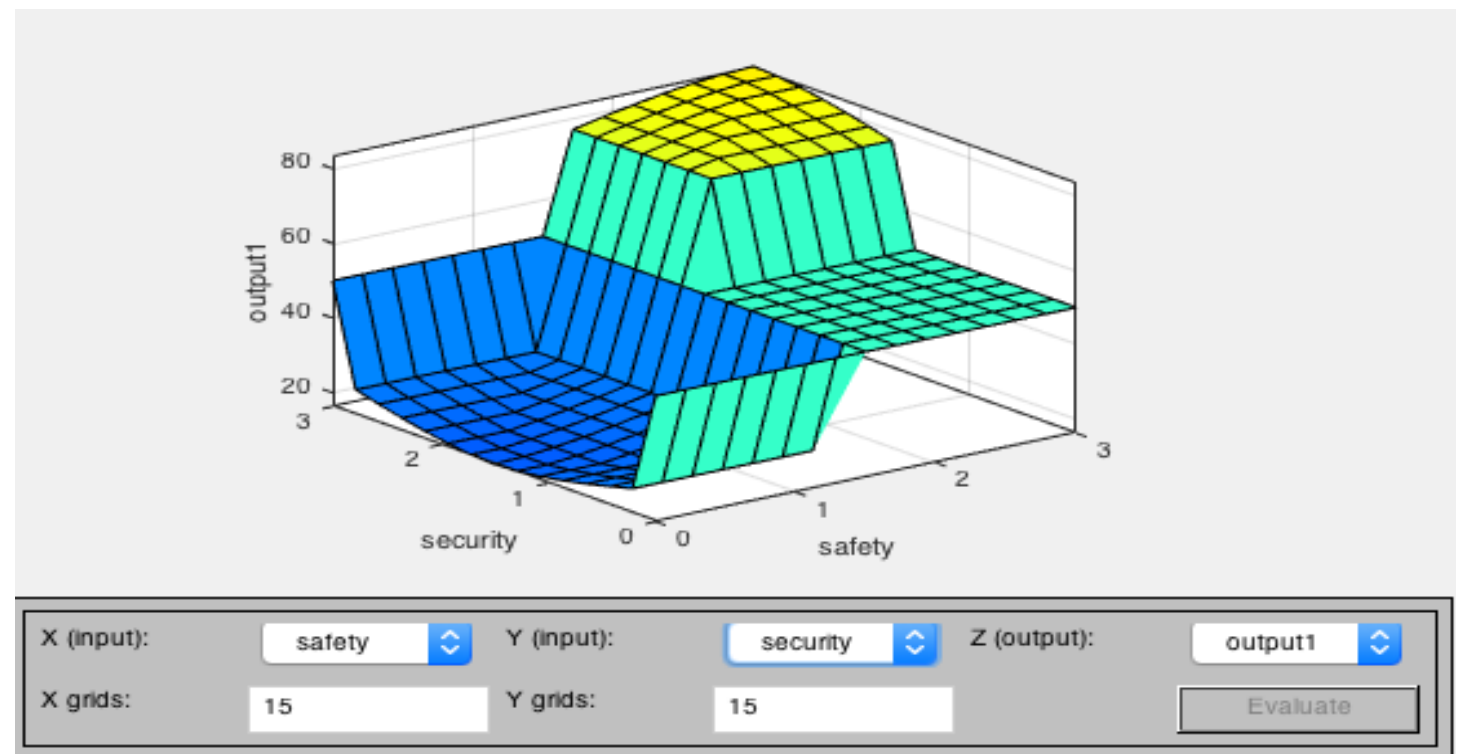

Figure 7. Output representation based on decision rules

Table 5. Weighting of criteria

\begin{tabular}{lccccccccc}
\hline & & Sf & & Sc & & Q & & C & Weight_criteria \\
\hline Sf & 0,075 & 1 & 0,093 & $1 / 7$ & 0,032 & $1 / 5$ & 0,188 & 3 & 0,097 \\
Sc & 0,525 & 7 & 0,648 & 1 & 0,788 & 5 & 0,313 & 5 & 0,568 \\
$\mathbf{Q}$ & 0,375 & 5 & 0,130 & $1 / 5$ & 0,158 & 1 & 0,438 & 7 & 0,275 \\
$\mathbf{C}$ & 0,025 & $1 / 3$ & 0,130 & $1 / 5$ & 0,023 & $1 / 7$ & 0,063 & 1 & 0,060 \\
\hline
\end{tabular}

Then, the LSPs are evaluated regarding their values of four criteria and ranking of each LSP is obtained in this section shown in Table 6. 6. LSP is assigned as the optimum provider and 21.LSP is assigned as the last provider to select. 
Table 6. Results of LSP

\begin{tabular}{lcccccc}
\hline & Safety & Security & Quality & Cost & Total & Ranking \\
\hline 1. LSP & 0,005 & 0,030 & 0,016 & 0,004 & 0,055 & 0,071 \\
2. LSP & 0,005 & 0,029 & 0,013 & 0,003 & 0,049 & 0,069 \\
3. LSP & 0,005 & 0,027 & 0,013 & 0,003 & 0,048 & 0,069 \\
4. LSP & 0,005 & 0,030 & 0,015 & 0,003 & 0,053 & 0,062 \\
5. LSP & 0,004 & 0,023 & 0,012 & 0,002 & 0,041 & 0,055 \\
6. LSP & 0,007 & 0,040 & 0,019 & 0,004 & 0,071 & 0,053 \\
7. LSP & 0,007 & 0,038 & 0,020 & 0,004 & 0,069 & 0,049 \\
8. LSP & 0,005 & 0,027 & 0,013 & 0,003 & 0,047 & 0,049 \\
9. LSP & 0,006 & 0,035 & 0,017 & 0,004 & 0,062 & 0,049 \\
10. LSP & 0,003 & 0,020 & 0,010 & 0,002 & 0,036 & 0,048 \\
11. LSP & 0,005 & 0,027 & 0,013 & 0,003 & 0,047 & 0,047 \\
12. LSP & 0,005 & 0,027 & 0,013 & 0,003 & 0,049 & 0,047 \\
13. LSP & 0,004 & 0,022 & 0,011 & 0,002 & 0,039 & 0,045 \\
14. LSP & 0,007 & 0,039 & 0,019 & 0,004 & 0,069 & 0,041 \\
15. LSP & 0,004 & 0,023 & 0,011 & 0,002 & 0,041 & 0,041 \\
16. LSP & 0,003 & 0,018 & 0,008 & 0,002 & 0,031 & 0,039 \\
17. LSP & 0,004 & 0,026 & 0,012 & 0,003 & 0,045 & 0,038 \\
18. LSP & 0,005 & 0,029 & 0,013 & 0,003 & 0,049 & 0,036 \\
19. LSP & 0,003 & 0,020 & 0,009 & 0,002 & 0,034 & 0,034 \\
20. LSP & 0,004 & 0,021 & 0,010 & 0,002 & 0,038 & 0,031 \\
21. LSP & 0,009 & 0,015 & 0,007 & 0,002 & 0,027 & 0,027 \\
\hline
\end{tabular}

\section{Comparison of the obtained results}

A comparative analysis of AHP and fuzzy logic is conducted considering the criteria prioritization to select the best LSPs. Both methods provide the different rankings. AHP produces this ranking order: Security, quality, safety and cost. Fuzzy logic approach presents the rankings the most important criteria as safety and security, and quality and cost are not important comparing the safety and security. For final selection, ranking the LSPs is necessary. LSPs are evaluated regarding their values of four criteria and 6. LSP is assigned as the optimum provider and 21.LSP is assigned as the last provider to select. In addition, sensitivity analysis is conducted to demonstrate the effectiveness of the criteria weights. The analysis is conducted by changing the only security weights and keeping constant the other criteria weights. The optimum provider and last provider are obtained again as 6. LSP and 21. LSP, respectively while some changes are obtained in the other rankings. Also, the analysis is conducted by changing the only safety weights and keeping constant the other criteria weights. The optimum provider and last provider are obtained again as 14 . LSP with 0,07 value and 21 . LSP with 0,02 value, respectively. Finally, two criteria are used to perform the sensitivity analysis and results produce that safety is most effective criteria on the computational results.

\section{CONCLUSION}

Nowadays, integration of business processes and real-world practices is a requirement. Incorporating of Logistics 4.0 implications into transportation process is an important stage. Selection of LSPs affects the all processes since it is related with company's main objective. This paper provides two methods to evaluate and select the LSP. In this paper, a process of transportation planning considering various criteria in relation to the challenges of Logistics 4.0 is addressed. This approach is useful tool for decision-making systems taking into account global competition and trends. In this context, AHP is conducted to evaluate the selection the LSPs which are one of the critical steps of the transportation network. The results of Fuzzy approach indicate that safety and security are best criteria while the results of AHP give the security and quality as two best criteria. The differences are related 
with the explanations of scoring by the experts. Ahp uses numerical values to evaluate the criteria and Fuzzy proposes linguistic regarding practical view, proposed methods can be used in the real-case applications. The main contribution is combination of safety, security parameters and industry 4.0 values that allows selecting the best provider ensuring all criteria. This paper addresses four main criteria for LSP selection under twenty sub criteria. Fuzzy approach is used to evaluate the criteria with linguistics variables. Also, a real case study is provided to demonstrate the impact of solution. To summarize, main findings of the study is to determinate the importance weights of criteria to analyze the LSPs using AHP which forms complex LSP problem into a hierarchical structure and fuzzy logic which ensures the subjectiveness for decision making. The future works can be conducted with different state of the art MCDM approaches to validate the results. In addition, human and ecological risks can be included to the criteria list. Also, proposed methods can be further used to handle other decision making problems such as outsourcing options, logistics chain process, inventory-routing problems. This paper includes the experts' decisions on past performances of LSPs as the limitation of paper. The other limitation is the analysis of the data used in the paper conducted by a small group of experts.

\section{REFERENCES}

Abdulhasan MJ, Hanafiah MM, Satchet MS, Abdulaali HS, Toriman ME, Al-Raad AA, 2019. Combining gis, fuzzy logic, and ahp models for solid waste disposal site selection in Nasiriyah, Iraq. Applied Ecology and Environmental Research 17(3): 6701-6722.

Barreto L, Amaral A, Pereira T, 2017. Industry 4.0 implications in logistics: an overview. Procedia Manufacturing 13: 1245-1252.

Erdogan M, Ozkan B, Karasan A, Kaya I, 2018. Selecting the best strategy for industry 4.0 applications with a case study. In Industrial Engineering in the Industry 4.0 Era (pp. 109-119). Springer, Cham.

Göçmen E, Erol R, 2018. The transition to industry 4.0 in one of the Turkish logistics company. International Journal of 3d Printing Technologies and Digital Industry 2(1): 76-85.

Gürcan ÖF, Yazıcı İ, Beyca ÖF, Arslan ÇY, Eldemir, F, 2016. Third party logistics (3PL) provider selection with AHP application. Procedia-Social and Behavioral Sciences 235: 226-234.

Hasan MM, Jiang D, Ullah AS, Noor-E-Alam M, 2020. Resilient supplier selection in logistics 4.0 with heterogeneous information. Expert Systems with Applications 139: 112799.

Jain V, Sangaiah AK, Sakhuja S, Thoduka N, Aggarwal R, 2018. Supplier selection using fuzzy AHP and TOPSIS: a case study in the Indian automotive industry. Neural Computing and Applications 29(7): 555-564.

Kadam A, Karnewar AS, Umrikar B, Sankhua RN, 2019. Hydrological response-based watershed prioritization in semiarid, basaltic region of western India using frequency ratio, fuzzy logic and AHP method. Environment, Development and Sustainability 21(4): 1809-1833.

Kauf S, 2016. City logistics-a strategic element of sustainable urban development. Transportation Research Procedia 16: $158-164$.

Li YL, Ying CS, Chin KS, Yang HT, Xu J, 2018. Third-party reverse logistics provider selection approach based on hybrid-information MCDM and cumulative prospect theory. Journal of Cleaner Production 195: 573-584.

Luthra S, Mangla SK, 2018. Evaluating challenges to Industry 4.0 initiatives for supply chain sustainability in emerging economies. Process Safety and Environmental Protection 117:168-179.

Memari A, Dargi A, Jokar MRA, Ahmad R, Rahim ARA, 2019. Sustainable supplier selection: A multi-criteria intuitionistic fuzzy TOPSIS method. Journal of Manufacturing Systems 50: 9-24.

Pamucar D, Chatterjee K, Zavadskas EK, 2019. Assessment of third-party logistics provider using multi-criteria decision-making approach based on interval rough numbers. Computers \& Industrial Engineering 127: 383-407. 
Prakash C, Barua MK, 2015. Integration of AHP-TOPSIS method for prioritizing the solutions of reverse logistics adoption to overcome its barriers under fuzzy environment. Journal of Manufacturing Systems 37: 599-615.

Simon J, Trojanova M, Zbihlej J, Sarosi J, 2018. Mass customization model in food industry using industry 4.0 standard with fuzzy-based multi-criteria decision making methodology. Advances in Mechanical Engineering 10(3): 1687814018766776.

Stević Ž, Pamučar D, Puška A, Chatterjee P. 2020. Sustainable supplier selection in healthcare industries using a new MCDM method: Measurement of alternatives and ranking according to COmpromise solution (MARCOS). Computers \& Industrial Engineering 140: 106231.

Tadić S, Zečević S, Krstić M, 2014. A novel hybrid MCDM model based on fuzzy DEMATEL, fuzzy ANP and fuzzy VIKOR for city logistics concept selection. Expert Systems with Applications 41(18): 8112-8128.

Wind Y, Saaty TL, 1980. Marketing applications of the analytic hierarchy process. Management science 26(7): 641658.

APPENDIX. Weighting of LSP based on Safety criteria

\begin{tabular}{|c|c|c|c|c|c|c|c|c|c|c|c|c|c|c|c|c|c|c|c|c|c|c|c|}
\hline & & & & & & & & & & & & & & & & & & & & & & Weight & \\
\hline $\begin{array}{c}1 . \\
\text { LSP }\end{array}$ & 0,023 & 0,062 & 0,113 & 0,003 & 0,129 & 0,005 & 0,007 & 0,056 & 0,005 & 0,095 & 0,078 & 0,003 & 0,098 & 0,015 & 0,071 & $0,079 \mid$ & 0,049 & 0,002 & 0,138 & 0,073 & 0,004 & 0,053 & 0,005 \\
\hline \begin{tabular}{c|}
2. \\
LSP \\
\end{tabular} & 0,008 & 0,021 & 0,068 & 0,104 & 0,100 & 0,007 & 0,003 & 0,004 & 0,003 & 0,095 & 0,009 & 0,079 & 0,042 & 0,009 & 0,003 & 0,143 & 0,115 & 0,005 & 0,077 & 0,073 & 0,083 & 0,050 & 0,005 \\
\hline \begin{tabular}{c|}
3. \\
LSP \\
\end{tabular} & 0,005 & 0,007 & 0,023 & 0,062 & 0,129 & 0,005 & 0,007 & 0,056 & 0,005 & 0,095 & 0,078 & 0,003 & 0,098 & 0,015 & 0,071 & 0,079 & 0,049 & 0,002 & 0,138 & 0,073 & 0,004 & 0,048 & 0,005 \\
\hline \begin{tabular}{c|}
4. \\
LSP
\end{tabular} & 0,160 & 0,004 & 0,008 & 0,021 & 0,072 & 0,005 & 0,199 & 0,003 & 0,009 & 0,041 & $|0,005|$ & 0,111 & 0,042 & 0,009 & 0,099 & 0,005 & 0,082 & 0,078 & 0,046 & 0,002 & 0,107 & 0,053 & 0,005 \\
\hline \begin{tabular}{c|}
5. \\
LSP
\end{tabular} & 0,003 & 0,003 & 0,003 & 0,004 & 0,014 & 0,005 & 0,199 & 0,003 & 0,009 & 0,041 & 0,005 & 0,111 & 0,042 & 0,009 & 0,099 & 0,005 & 0,082 & 0,078 & 0,046 & 0,002 & 0,107 & 0,041 & 0,004 \\
\hline \begin{tabular}{c|}
6. \\
LSP \\
\end{tabular} & 0,160 & 0,104 & 0,158 & 0,145 & 0,100 & 0,034 & 0,007 & 0,056 & 0,005 & 0,095 & 0,078 & 0,003 & 0,098 & 0,015 & 0,071 & 0,079 & 0,049 & 0,002 & 0,138 & 0,073 & 0,004 & 0,070 & 0,007 \\
\hline \begin{tabular}{c|}
7. \\
LSP
\end{tabular} & 0,069 & 0,145 & 0,068 & 0,002 & 0,002 & 0,101 & 0,022 & 0,056 & 0,232 & 0,002 & 0,009 & 0,047 & 0,003 & 0,308 & 0,043 & 0,003 & 0,115 & 0,005 & 0,077 & 0,073 & 0,036 & 0,067 & 0,007 \\
\hline \begin{tabular}{c|}
8. \\
LSP \\
\end{tabular} & 0,008 & 0,104 & 0,008 & 0,145 & 0,100 & 0,011 & 0,007 & 0,019 & 0,077 & 0,068 & 0,182 & 0,003 & 0,002 & 0,009 & 0,002 & 0,111 & 0,005 & 0,078 & 0,046 & 0,003 & 0,002 & 0,047 & 0,005 \\
\hline $\begin{array}{c}9 . \\
\text { LSP }\end{array}$ & 0,115 & 0,187 & 0,113 & 0,062 & 0,043 & 0,168 & 0,002 & 0,006 & 0,026 & 0,122 & 0,004 & 0,005 & 0,042 & 0,009 & 0,099 & 0,048 & 0,003 & 0,110 & 0,005 & 0,073 & 0,059 & 0,062 & 0,006 \\
\hline $\begin{array}{l}10 . \\
\text { LSP } \\
\end{array}$ & 0,003 & 0,003 & 0,003 & 0,007 & 0,005 & 0,005 & 0,155 & 0,004 & 0,003 & 0,014 & 0,078 & 0,142 & 0,002 & 0,015 & 0,043 & $0,003 \mid$ & 0,115 & 0,047 & 0,003 & 0,102 & 0,004 & 0,036 & 0,003 \\
\hline \begin{tabular}{c|}
11. \\
LSP \\
\end{tabular} & 0,008 & 0,062 & 0,008 & 0,104 & 0,072 & 0,011 & 0,066 & 0,003 & 0,180 & 0,005 & 0,026 & 0,005 & 0,042 & 0,009 & 0,099 & 0,048 & 0,003 & 0,110 & 0,005 & 0,073 & 0,059 &, 047 & 0,005 \\
\hline \begin{tabular}{c|}
12. \\
LSP \\
\end{tabular} & 0,115 & 0,004 & 0,113 & 0,003 & 0,002 & 0,168 & 0,007 & 0,093 & 0,077 & 0,002 & 0,078 & 0,016 & 0,098 & 0,009 & 0,002 & $0,003 \mid$ & 0,002 & 0,110 & 0,005 & 0,073 & 0,036 & 0,048 & 0,005 \\
\hline $\begin{array}{c}13 . \\
\text { LSP } \\
\end{array}$ & 0,003 & 0,007 & 0,003 & $\mid 0,007$ & 0,005 & 0,005 & 0,110 & 0,130 & 0,009 & 0,095 & 0,009 & 0,002 & 0,014 & 0,132 & 0,071 & 0,111 & 0,003 & 0,002 & 0,003 & 0,002 & 0,083 & 0,038 & 0,004 \\
\hline $\begin{array}{l}14 . \\
\text { LSP } \\
\end{array}$ & 0,069 & 0,104 & 0,068 & 0,104 & 0,072 & 0,101 & 0,003 & 0,093 & 0,129 & 0,041 & 0,130 & 0,079 & 0,005 & 0,044 & 0,099 & 0,048 & 0,003 & 0,110 & 0,005 & 0,073 & 0,059 & 0,068 & 0,007 \\
\hline $\begin{array}{c}15 . \\
\text { LSP } \\
\end{array}$ & 0,005 & 0,104 & 0,005 & 0,003 & 0,002 & 0,007 & 0,007 & 0,167 & 0,004 & 0,005 & 0,004 & 0,111 & 0,003 & 0,006 & 0,01 & 0,07 & 0,082 & 0,047 & 0,002 & 0,132 & 0,059 & 0,040 & 0,004 \\
\hline $\begin{array}{l}16 . \\
\text { LSP } \\
\end{array}$ & 0,005 & 0,002 & 0,005 & 0,062 & 0,043 & 0,007 & 0,110 & 0,003 & 0,009 & 0,068 & 0,009 & 0,079 & 0,002 & 0,015 & 0,003 & 0,016 & 0,049 & 0,003 & 0,108 & 0,005 & 0,059 & 0,031 & 0,003 \\
\hline $\begin{array}{l}17 . \\
\text { LSP } \\
\end{array}$ & 0,008 & 0,003 & 0,008 & 0,004 & 0,003 & 0,011 & 0,003 & 0,056 & 0,129 & 0,002 & 0,130 & 0,142 & 0,070 & 0,220 & 0,003 & 0,005 & 0,016 & 0,078 & 0,046 & 0,003 & 0,002 & 0,045 & 0,004 \\
\hline $\begin{array}{c}18 . \\
\text { LSP } \\
\end{array}$ & 0,160 & 0,062 & 0,158 & 0,004 & 0,003 & 0,235 & 0,066 & 0,004 & 0,004 & 0,005 & 0,004 & 0,002 & 0,098 & 0,006 & 0,005 & 0,079 & 0,003 & 0,016 & 0,046 & 0,002 & 0,107 & 0,051 & 0,005 \\
\hline $\begin{array}{c}19 . \\
\text { LSP } \\
\end{array}$ & 0,003 & 0,004 & 0,003 & 0,007 & 0,005 & 0,004 & 0,004 & 0,006 & 0,077 & 0,068 & 0,078 & 0,047 & 0,070 & 0,132 & 0,099 & 0,002 & 0,005 & 0,005 & 0,015 & 0,073 & 0,004 & 0,034 & 0,003 \\
\hline $\begin{array}{l}20 . \\
\text { LSP } \\
\end{array}$ & 0,005 & 0,004 & 0,005 & 0,145 & 0,100 & 0,007 & 0,004 & 0,093 & 0,005 & 0,002 & 0,005 & 0,003 & 0,126 & 0,009 & 0,002 & 0,048 & 0,082 & 0,110 & 0,003 & 0,015 & 0,107 & 0,042 & 0,004 \\
\hline $\begin{array}{c}21 . \\
\text { LSP }\end{array}$ & 0,069 & 0,003 & 0,068 & 0,002 & 0,002 & 0,101 & 0,007 & 0,093 & 0,005 & 0,041 & 0,005 & 0,005 & 0,002 & 0,009 & 0,003 & $0,003 \mid$ & 0,082 & 0,002 & 0,046 & 0,002 & 0,012 & 0,027 & 0,009 \\
\hline
\end{tabular}

